\title{
Odor-taste interactions in food perception: Exposure protocol shows no effects of associative learning
}

\author{
Robin Fondberg ${ }^{\mathrm{a}^{*}}$, Johan N Lundström ${ }^{\mathrm{a}, \mathrm{b}, \mathrm{c}, \mathrm{d}}$, Janina Seubert ${ }^{\mathrm{a}}$ \\ ${ }^{a}$ Department of Clinical Neuroscience, Karolinska Institutet, Sweden; ${ }^{b}$ Monell Chemical Senses Center, Philadelphia, USA; \\ ${ }^{\mathrm{c}}$ Department of Psychology, University of Pennsylvania, USA; ${ }^{\mathrm{d}}$ Stockholm University Brain Imaging Centre, Sweden
}

*Contact: robin.fondberg@gmail.com

\begin{abstract}
Repeated exposure can change the perceptual and hedonic experience of food flavors. Associative learning during which a flavor's odor component is affected by co-exposure with taste is thought to play a central role in this process. However, changes can also arise due to mere-exposure to the odor in itself. The aim of this study was to dissociate effects of associative learning from effects of mere-exposure by repeatedly presenting one odor together with a sweet taste and another without. Sixty individuals participated in two testing sessions separated by an exposure phase during which the stimuli were presented as flavorants in chewing gums. The gums were chewed three times per day for five days. Ratings of odor sweetness, odor pleasantness, odor intensity enhancement by taste, and odor referral to the mouth were collected at both sessions. Consistent with the idea of mere-exposure, odor pleasantness increased between the sessions independently of whether the odor had been exposed with or without sucrose. However, contrary to expectation, we found no evidence for associative learning effects on any of the outcomes. In addition, exploratory equivalence tests demonstrated that these effects were either absent or insignificant in magnitude. Taken together, our results suggest that associative learning effects on odor-taste interaction are either smaller than previously thought or highly dependent on the experimental setting. Future studies are needed to dissociate these two possibilities and, if experimental settings can be identified that reliably produce such effects, to pinpoint boundary conditions that prevents associative learning from taking place.
\end{abstract}

Keywords: flavor binding, associative learning, odor-taste learning, mere-exposure, conditioning

\section{Conflicts of interest}

The authors have no relevant interests to declare. 


\section{Introduction}

Past experience helps our perceptual system to integrate sensory information from distinct modalities into a coherent percept with semantic and hedonic features (Lewkowicz \& Ghazanfar, 2009). For example, frequent exposure to specific odor-taste combinations changes how their combined percept, the food's flavor, is perceived and evaluated. These perceptual changes are thought to be central for survival, as they promote consumption of familiar foods items that have been determined through experience to be safe and nutritious. Associative learning within the olfactory and gustatory network has been proposed to account for effects of exposure on flavor perception (Prescott, 1999). However, very features of flavor have been directly manipulated in associative learning-paradigms.

Flavors are holistic percepts that arise from inside the mouth during food consumption (Spence, 2016). They rely on cortical integration of odor and taste signals that have been processed separately in the peripheral nervous system before reaching the cortex (Doty, 2019). Observations from everyday life indicate that repeated exposure to specific odor-taste mixtures during habitual food consumption modulates how the odor is subsequently perceived when presented alone. Most notably, some odors that are often experienced in combination with sweet taste, such as strawberry or vanilla, are frequently described as "smelling sweet" (Dravnieks, 1985). In addition to affecting our experiences of unisensory odors, there is reason to believe that exposure to odor-taste mixtures also affects how their sensory components interact when subsequently presented together. Specifically, flavor percepts are perceived and hedonically evaluated based on the extent to which the specific combination of unisensory components resembles a familiar food item (e.g Lim \& Johnson, 2012; Schifferstein \& Verlegh, 1996). Three such phenomena have been frequently described in the literature:

First, the degree of familiarity of an odor-taste mixture affects its hedonic value (Fondberg et al., 2018; Schifferstein \& Verlegh, 1996; Small et al., 2004). By presenting different odor-taste mixtures in water solutions to the mouth, familiar combinations (e.g. vanilla odor+sweet taste or chicken odor+salty taste) have repeatedly been found to be more palatable than unfamiliar combinations (e.g. vanilla + salty or chicken+sweet).

Second, presenting a taste together with an odor will enhance the intensity of the odor, but only if that specific odor-taste combination has been frequently perceived in the past (Fujimaru \& Lim, 2013; Green et al., 2012; Lim et al., 2014; Linscott \& Lim, 2016). For example, adding sucrose to a vanillin solution enhances the perceived intensity of the vanilla odor, while adding salt does not.

The third phenomenon is the olfactory location illusion, often labeled as odor referral, in which the odor component of flavor is perceived as originating from the mouth (Hollingworth \& Poffenberger Jr., 1917; Rozin, 1982; Spence, 2016). For example, the vanilla odor of vanilla custard is, just like its sweet taste, experienced in the mouth and not in the nasal cavity where the olfactory receptors are located. This perceptual illusion occurs more frequently when the odor-taste combination is familiar then when it is unfamiliar (Fondberg et al., 2018; Lim et al., 2014; Lim \& Johnson, 2011, 2012; but see also Stevenson et al., 2011).

Both perceived odor sweetness and the effects of familiarity on flavor perception are 
typically interpreted within the broader framework of associative learning (Prescott, 2012; Stevenson, 2014). This idea is based on the realization that consumption of any food item will cause synchronized stimulation with its specific and stable odor and taste qualities. When a combination is encountered often, such as vanilla and sweet, an associative link will be formed between the two. The unisensory odor and taste qualities in combination with the newly formed multisensory associations will then determine the coherent flavor experience of the food item (Stevenson \& Oaten, 2010). Within this framework, the perceived sweetness of vanilla odor is thought to reflect the strength of its association with sweet taste.

Research on the other senses has revealed that mere-exposure to unisensory stimuli also can have enduring effects on both perceptual and hedonic aspects of our experiences (Bornstein, 1989). Associative learning effects can be separated from mereexposure effects by comparing responses to odors that have been presented with taste to responses to odors that have been presented without taste. While this experimental set-up is straightforward in theory, delivering chemosensory stimuli with the necessary control has been shown to be a non-trivial task. Indeed, to date, learning-dependent aspects of flavor perception have only been studied by a few research groups and results have been mixed. Out of the four abovementioned phenomena that have been hypothesized to be driven by associative learning, research on odor sweetness has produced the most consistent results. Several studies have reported that repeated exposure with sucrose can make odors smell sweeter (Prescott et al., 2004; Prescott \& Murphy, 2009; Privitera et al., 2012; Stevenson et al., 1995, 1998, 2000a, 2000b; Stevenson \&
Case, 2003; Stevenson \& Mahmut, 2011a, 2011b; Yeomans et al., 2009; Yeomans \& Boakes, 2016). This effect has typically not been observed for odors that have been presented without an accompanying sweet taste. Only one study has used this paradigm without finding effects on odor sweetness (Sundqvist et al., 2006).

Results are less clear for potential pleasantness effects. Some studies indicate that the positive or negative hedonic values of sweet or bitter tastes indeed can be transferred to odors following exposure to odor-taste mixtures (Baeyens et al., 1990, 1995, 1996; Barkat et al., 2008; Dickinson \& Brown, 2007; Mundy et al., 2006; Prescott \& Murphy, 2009; Privitera et al., 2012; Ruszpel \& Gast, 2020; Stevenson \& Case, 2003; van den Bosch et al., 2015; Wardle et al., 2007; Yeomans et al., 2009; Yeomans \& Boakes, 2016; Zellner et al., 1983), but other studies have not found these effects (Baeyens et al., 1990; Barkat et al., 2008; Stevenson et al., 1995, 1998, 2000a, 2000b; Stevenson \& Mahmut, 2011a, 2011b; Sundqvist et al., 2006; van den Bosch et al., 2015). These conflicting results may be explained by interindividual differences in taste preferences. This notion has gained support from a study where odor pleasantness indeed increased more after exposure with sucrose than after exposure without taste, but only for participants that liked sweet taste to begin with (Yeomans, 2006).

Evidence for associative learning effects on intensity is weak. Some studies indicate that unisensory odors are rated as more intense following exposure with taste than after exposure without taste (Stevenson et al., 1995, 1998, 2000a). However, one study has reported an effect the opposite direction (van den Bosch et al., 2015), and several studies did not find any significant effects at all (Labbe \& Martin, 2009; 
Stevenson et al., 1995, 2000a, 2000b; Stevenson \& Case, 2003; Stevenson \& Mahmut, 2011b; Sundqvist et al., 2006; Yeomans et al., 2009; Yeomans \& Boakes, 2016). These studies provide no conclusive evidence that associative learning influences the intensity of unisensory odors. However, it has been suggested that the intensity enhancement resulting from presenting a taste together with an odor might vary depending on how often the combination has been perceived in the past (Fujimaru \& Lim, 2013; Green et al., 2012; Lim et al., 2014; Linscott \& Lim, 2016). No exposure protocol to date has been designed to test this notion. Similarly, potential effects of associative learning on odor referral to the mouth remain to be determined.

While there is little doubt that experience is important for how we perceive and emotionally respond to foods, it is still not clear to what degree odor-taste interactions rely on the formation of associations between the olfactory and gustatory modalities, how easily such associations are formed, and how strong the potential associative learning effects are in relation to mere-exposure effects. The aim of the present study is therefore to conceptually replicate the previously reported associative learning effects on odor sweetness and odor pleasantness and dissociate them from mereexposure effects. In addition, we will directly test whether odor-taste associative learning also affects odor intensity enhancement by taste, and the likelihood of odor referral to the mouth. Hence, four hypotheses will be tested:

1. Perceived odor sweetness will increase more after exposure with a sweet taste than after exposure without taste (associative learning).

2. Perceived odor pleasantness will increase following exposure independently of whether the odor has been exposed with or without sweet taste (mere-exposure). The degree to which participants like sweet taste will determine whether exposure with sucrose results in a larger increase than exposure without taste, i. e. the increase in pleasantness of sweet-paired odors will be larger than the increase of mere-exposure odors for participants that like sweet taste (associative learning).

3. Adding a sweet taste to an odor solution will enhance the intensity of the combined solution more if the odor has been previously exposed with sweet taste, than if it has been exposed without taste (associative learning).

4. Odor referral to the oral cavity and tongue will occur more frequently if the odor has been exposed with sweet taste, than if it has been exposed without taste (associative learning).

In line with previous studies, Hypothesis 1 will be tested using orthonasal odors presented via the nostrils, while Hypotheses 2-4 will be tested using retronasal odor solutions presented via the mouth and nasopharynx with (3 and 4) or without (2) sucrose.

\section{Method}

\section{Participants}

Data collection was terminated when 60 individuals $\left(40\right.$ women, $M_{\text {age }}=27.31$, $S D_{\text {age }}=5.05$ ) had completed both testing sessions. The sample size was determined a priori. One individual did not return for the second session and was therefore not included in the final sample; hence, 61 individuals in total were recruited through an online testing recruitment system hosted by Karolinska Institutet. To be eligible, participants had to be 18-45 years old and speak English. Exclusion criteria were 
tobacco use, current cold or flu symptoms, self-reported taste or smell dysfunction, and less than 11 out of 16 points on an olfactory screening test where 10 or below indicates olfactory dysfunction (Sniffin' Sticks, Hummel, Sekinger, Wolf, Pauli, Kobal, 1997). All participants provided written informed consent and received a small payment on completion. Participants were asked not to eat or drink flavored beverages one hour before each testing session to limit potential odor acuity effects. The study was approved by the Regional Ethics Review Board in Stockholm. Data was collected in the fall-winter of 2019.

\section{Preregistration and data/material availability}

Study preregistration, the PsychoPy scripts used to control the experiment and collect responses, the study protocol, and stimulus recipes are all available on OSF (Open Science Framework, https://osf.io/dtv8s/). Raw data is available on request due to confidentiality restrictions in the ethics protocol.

\section{Stimuli}

\section{Odor selection}

Two odorants, basil (Basil oil, Stockholms Aeter Essencefabrik AB) and orange flower (Orange flower oil, Stockholms Aeter Essencefabrik $\mathrm{AB}$ ), were selected from a large set of odorants to be clearly distinguishable from each other, not identifiable, neutrally valenced, and tasteless when dissolved in water.

Odorants were presented both orthonasally (sniffed from bottles when assessing odor sweetness) and retronasally (sipped from medicine cups when assessing the other outcomes) in different concentrations. All odor and taste stimuli were made freshly every $48 \mathrm{~h}$, stored at $6^{\circ} \mathrm{C}$ in sealed glass containers, and presented at room temperature.

\section{Taste and retronasal odorants}

Retronasal odorants were produced by dissolving the odorous oils in $96 \%$ ethanol $(0.48 \%$ volume/volume $[\mathrm{v} / \mathrm{v}])$ and then diluting the solvents to target concentrations with water. The alcohol was not consciously detectable in any of the stimuli. Concentrations of the retronasal basil $(0.0029 \% \mathrm{v} / \mathrm{v})$ and orange flower $(0.0043 \%$ $\mathrm{v} / \mathrm{v})$ odorants were selected through pilot testing $(n=10)$ to be clearly perceivable but not to evoke any gustatory or trigeminal sensations. To produce combined odor-taste stimuli, sucrose was added to each of the two odorants at a concentration that perceptually mimicked moderately sweet drinks $(1.19 \%$ weight/volume $[\mathrm{w} / \mathrm{v}])$. In addition to the two pure odorants and the two odor-sucrose solutions, participants were also presented with the pure tastant (sucrose and water, $1.19 \% \mathrm{w} / \mathrm{v}$ ), and plain water as a control.

The widespread belief that sweetness is universally liked has been challenged by studies demonstrating distinct and highly diverse response patterns across individuals (Kim et al., 2017). To quantify interindividual variability in sweet-liking, an intensely sweet taste solution $(34.23 \% \mathrm{w} / \mathrm{v})$ was prepared by mixing sucrose and water. This concentration has been shown to optimally discriminate between different sweet-liking phenotypes (Iatridi et al., 2019). Finally, a retronasal citrus-like odorant used for practice was prepared by mixing citral $(0.0025 \% \mathrm{v} / \mathrm{v})$ and ethanol $(0.2 \% \mathrm{v} / \mathrm{v})$ with water.

\section{Orthonasal odorants}

The two orthonasal odorants were prepared by first dissolving the odorous oils in ethanol $(0.48 \% \mathrm{v} / \mathrm{v}$ for both basil and orange flower) and subsequently diluting the solutions to 
target concentrations with water $(0.033 \%$ $\mathrm{v} / \mathrm{v})$. Concentrations were determined through a pilot study $(n=10)$ to match the intensities of the retronasal odorants. An orthonasal citrus-like training odorant was then prepared in a similar fashion by mixing citral $(0.1 \% \mathrm{v} / \mathrm{v})$, ethanol $(4.0 \% \mathrm{v} / \mathrm{v})$, and water.

\section{Chewing gums}

Basil and orange flower flavored chewing gums were used to expose participants to the odors (with or without sweet taste) between the testing sessions. Four different flavor categories of gum were prepared: pure basil, basil-sucrose, pure orange flower, and orange flower-sucrose. The tasteless and odorless gum base (Glee Gum base, https://www.gleegum.com/) was heated until its melting point was reached. One of the odorous oils was then added, after which the gum dough was kneaded for at least 10 minutes. When the oil was evenly distributed and the dough had a firm consistency, it was cut into small pieces of $1.2 \mathrm{~g}( \pm 0.2 \mathrm{~g})$. Concentrations were selected to produce intensity matched (assessed in $n=10$ ) basil (400 micro g/100 g gum base) and orange flower (1250 microgram/100 g gum base) chewing gums that evoked distinct olfactory, but neither gustatory nor trigeminal sensations. The sweet chewing gums were made in the same way, but in addition to the odorous oil, sucrose was added at a concentration chosen to match commercially available sweet chewing gums (13.04\% $\mathrm{w} / \mathrm{w})$. Chewing gums were wrapped in baking paper and stored in plastic bags for no more than 4 weeks to preserve flavor.

\section{Procedure}

Participants attended two testing sessions of approximately $75 \mathrm{~min}$ that were spaced 5-11 days apart $(M=6.37, S D=1.57)$. At the end of the first session, participants were in alternating order either given 15 sweetened basil gums and 15 unsweetened orange flower gums, or 15 unsweetened basil gums and 15 sweetened orange flower gums. In each batch, the chewing gums of each flavor were numbered 1 to 15 .

During the next five days, subsequently referred to as the Exposure Phase, participants chewed six chewing gums per day: two before breakfast, two before lunch, and two before dinner (see Figure 1A). One of the two chewing gums was always sweetened, and the other unsweetened. We emphasized that all gums should be chewed before meals to maximize their salience. Participants were instructed to chew the first gum for 60 seconds, then pause for five minutes without eating and drinking, and then chew the other gum for 60 seconds. To avoid order effects, participants alternated between chewing the sweetened or the unsweetened gum first between days. Every night during the Exposure Phase, the participants texted one of the experiment leaders to confirm that all gums had been chewed. To ensure that no gum was skipped, participants were (incorrectly) told that one of the chewing gums could be salty. The instruction was that if they found the salty gum, they should mention the salty gum number in that night's text message. Participants that failed to send a text message were contacted without delay and reminded of the importance of sticking to the routine. Overall, compliance was high: all 60 participants contacted the experiment leader according to schedule, or no later than one day late, to confirm that all gums had been chewed and that none had been salty.

The pre and post-exposure sessions each contained three experiments that were separated by short pauses to minimize habituation. Before the experiments began, 
participants tasted the intensely sweet sucrose solution used to assess sweet-liking. While having $3 \mathrm{ml}$ of the solution in their mouth, the question "How much do you like this taste?" was displayed on the screen, together with a visual analogue scale with endpoint anchors "Not at all" and "Very much". After clicking on the scale, participants expectorated and rinsed thoroughly with water.

Experiment 1 assessed orthonasal odor sweetness, Experiment 2 retronasal odor pleasantness, and Experiment 3 both retronasal odor intensity enhancement by taste and retronasal odor referral to the mouth (see Figure 1B). To ensure that odor-sweet pairing would not affect the orthonasal sweetness ratings, all participants first completed Experiment 1. Then, to avoid order effects, the sequence of Experiment 2 and 3 was alternated between participants. Just before the beginning of each experiment, the upcoming task was explained in detail. Then, a practice trial with the citrus-like orthonasal (Experiment 1) or retronasal (Experiment 2, 3) training odorant was used to ensure that the participant understood the task and felt comfortable using the scales.
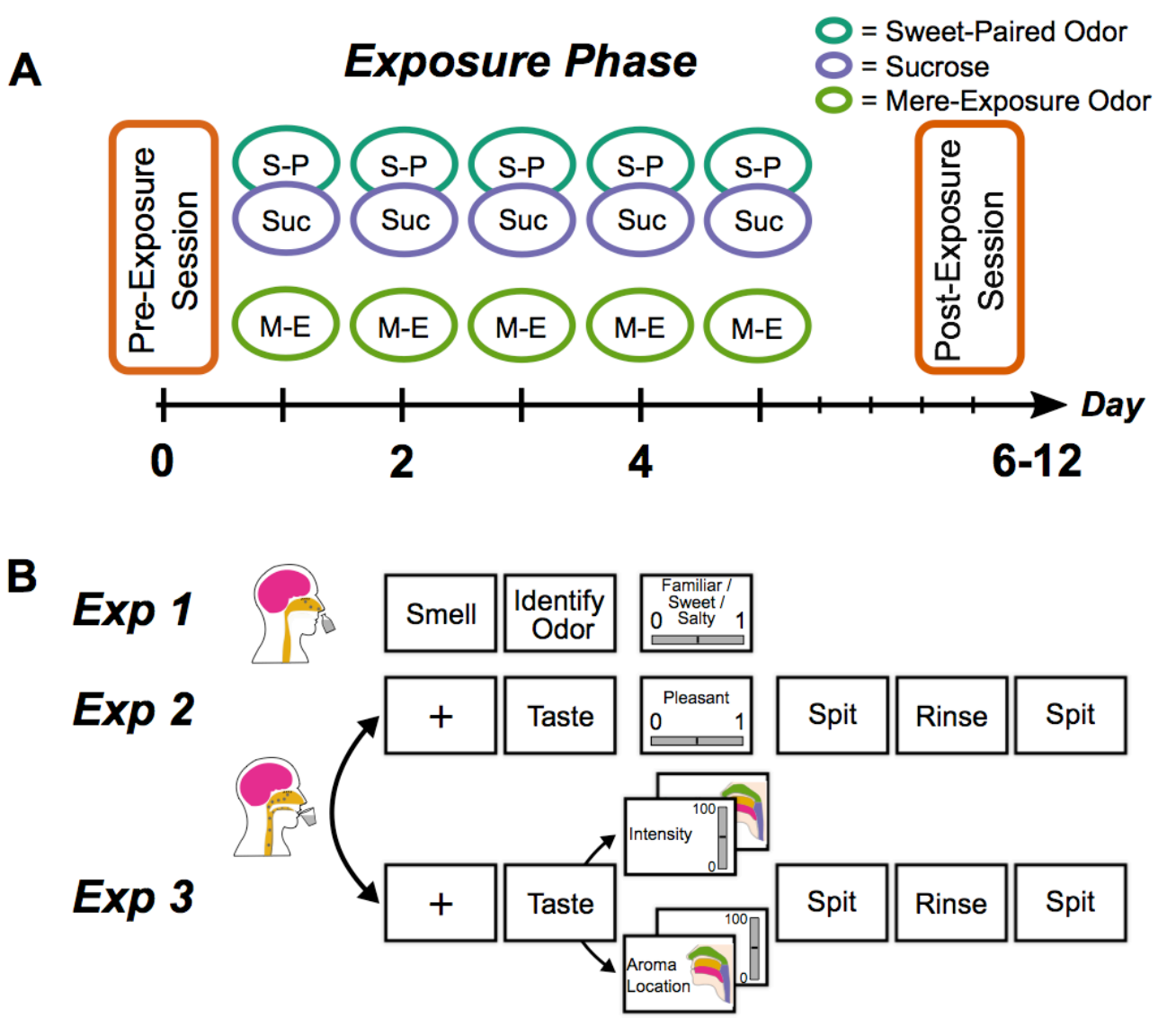

Figure 1. Procedure and trial design. (A) Timeline description of the testing procedure. Ratings were obtained during the preexposure and post-exposure sessions. A 5-day Exposure Phase separated the testing sessions during which participants chewed two types of chewing gums: one flavored with a (sweet-paired) odor and sucrose, and one flavored with a second (mereexposure) odor without sucrose. (B) Trial design of the three experiments. Experiment 1 (Exp 1) assessed odor sweetness, Experiment 2 (Exp 2) odor pleasantness, and Experiment 3 (Exp 3) odor intensity enhancement by taste and odor referral to the mouth. To avoid order effects, the sequence of Experiment 2 and 3 was alternated between participants and during Experiment 3, intensity and odor referral (aroma location) were assessed in random order. 


\section{Experiment 1: Odor sweetness}

This experiment assessed changes in orthonasal odor sweetness between the testing sessions. We only expected the perceived sweetness to increase for odors that had been paired with sucrose during the Exposure Phase (Hypothesis 1). After the practice trial, the basil and orange flower odorants were presented and rated one at a time. For each odorant, participants were instructed to open a bottle and sniff while placing the opening 2-3 cm below the nose. The first question to appear on the screen was "What does it smell like?" along with a textbox field for participants to provide a free form response. Next, three visual analog rating scales appeared on the same frame, each presented as a horizontal line placed across the top, middle or low section of the screen, respectively. The scales measured familiarity, sweetness and saltiness, in that order, and used "Not familiar/sweet/salty at all" and "Extremely familiar/sweet/salty" as endpoint anchors. Saltiness ratings were collected as a control to confirm that the effect of the Exposure Phase was tastespecific (these secondary results are presented in the Supplementary Material) and quality+familiarity ratings were collected to ensure that the odors were not identifiable at the first testing session. Clicking on a scale displayed a marker that could be dragged along the horizontal axis. Participants were allowed to smell the odorants as many times as necessary. This experiment ended when all three ratings had been completed.

\section{Experiment 2: Odor pleasantness}

This experiment assessed changes in retronasal odor pleasantness between the sessions and tested if the degree to which participants liked sweet taste modulated the potential amplifying effect of sweet-pairing (Hypothesis 2).
The two pure odorants, the two odorant-sucrose mixtures, the pure tastant, and plain water were presented twice in one out of four pseudo-randomized presentation orders (without repetitions). In total, this experiment thus contained 12 trials. Participants 1, 5, 9, [. . .] were assigned to presentation order 1, participants 2, 6, 10, [. . .] to order 2, etc. To further avoid order effects, presentation order 3 and 4 were created by reversing order 1 and 2 . Participants evaluated each stimulus by tasting a $3 \mathrm{ml}$ sample from a numbered medicine cup, and swishing the solution around in the mouth while breathing through the nose.

All trials had the same structure. They were initiated by a fixation cross $(3 \mathrm{~s})$, after which "Please taste cup no. X" appeared on the screen $(6.5 \mathrm{~s})$. While the participant had the stimulus solution in the mouth, the question "How much do you like this taste?" was displayed together with a visual analog scale with endpoint anchors "Not at all" and "Very much". Participants rated their hedonic experience by clicking on the scale. They were then instructed to expectorate the solutions $(5.5 \mathrm{~s})$, rinse with water $(7.5 \mathrm{~s})$, and expectorate again $(5.5 \mathrm{~s})$.

\section{Experiment 3: Odor intensity enhancement by taste and odor referral to the mouth}

This experiment tested two hypotheses ( 3 and 4): first, if changes between the sessions in odor intensity enhancement by taste was amplified by sweet pairing. Specifically, we expected that adding sucrose to an odor solution would result in a larger increase in perceived intensity at the second session than at the first session, but only for odors that had been paired with sucrose during the Exposure Phase. Second, if odor referral to the oral cavity and tongue increased between the sessions. Again, we only expected increased 
referral for odors that had been paired with sucrose during the Exposure Phase.

The same stimulus material and presentation order were used as in Experiment 2. Each trial began with a fixation cross ( $3 \mathrm{~s})$ that was followed by a prompt ( $7 \mathrm{~s})$ to taste the solution in one of the 12 numbered medicine cups. Two tasks were then presented consecutively in random order with a short pause $(0.5 \mathrm{~s})$ in between. One task required the participants to localize the sensation evoked by the solution's olfactory (aroma) component, while trying to ignore any taste sensations. To ensure correct task performance, participants were trained to separate the taste ("the sweet, salty, bitter, sour, or umami part of a flavor") from the odor/aroma ("any other flavor-like sensation") component of flavor just before the experiment began. For each trial, the question "Where do you perceive the aroma?" was displayed on the screen together with a cross-sectional illustration of a human head (adapted from Lim, Johnson, 2012) with the anatomical locations "Nose", "Oral cavity", "Tongue", and "Throat". Participants could select none, one, or several of the locations to indicate the perceived location of the odor component. The other task required participants to attend to the full flavor experience. "Rate the intensity of this beverage" was displayed on the screen, together with a labeled magnitude scale with the anchors "Barely detectable" and "Strongest imaginable". Clicking on the scale logged the response and immediately removed the image. After having completed both tasks with the solution in the mouth, participants were instructed to expectorate $(5.5 \mathrm{~s})$, rinse with water $(7.5 \mathrm{~s})$, and expectorate again $(5.5 \mathrm{~s})$.
Statistical analyses and data transformation

The code is available under "R scripts" at this study's OSF (https://osf.io/dtv8s/). Unless stated otherwise, analyses were carried out in accordance with the preregistered analysis plan.

\section{Predictor variables}

Session. Mean centered variable indicating whether the rating was collected at the "preexposure" (-0.5) or "post-exposure" (0.5) session.

Condition. Mean centered variable indicating whether the rated stimulus's odor component was presented with, "sweet-paired" $(0.5)$, or without, "mere-exposure" (-0.5), sucrose during the Exposure Phase.

Sweet-liking. Mean centered continuous variable containing each participant's average pleasantness rating of the intensely sweet sucrose solution across the two sessions. The original ratings were on a scale from 1 ("Not pleasant at all") to 100 ("Very pleasant").

\section{Outcome variables}

Odor sweetness. Orthonasal odor sweetness was denoted as a number between 0.01 ("Not sweet at all") and 1 ("Extremely sweet"), which corresponded to the selected location on the rating scale.

Odor pleasantness. Retronasal odor pleasantness was also denoted as a number between 0.01 ("Not pleasant at all") and 1 ("Very pleasant"), which again corresponded to the selected location on the rating scale.

Odor intensity enhancement (by taste). A difference score was defined to reflect the difference in intensity between a pure retronasal odor, and the same retronasal odor presented with sweet taste. This variable was obtained by subtracting the intensity rating for each odor solution from the respective intensity rating of the same odor solution 
when it also contained sucrose. Basil, basil+sucrose, orange flower, and orange flower+sucrose was each presented twice every session, which resulted in four unique difference scores (e.g. intensity[basil+sucrose] - intensity[basil]). The raw intensity ratings were on a scale from 1 ("Barely detectable") to 100 ("Strongest imaginable").

Odor referral to the oral cavity and tongue. Two separate binary localization indicators were used to specify whether or not the retronasal odor components of the odor+sucrose solutions had been perceived in the oral cavity (perceived in the oral cavity: 1 , not perceived in the oral cavity: 0 ) or tongue (perceived on the tongue: 1, not perceived on the tongue: 0 ).

\section{Analyses}

Mixed effects models were used to estimate the effects of Session ("pre-exposure", "postexposure"), Condition ("sweet-paired", "mere-exposure"), and their interaction. We used linear mixed effects models (LMM) to analyze odor sweetness, odor pleasantness, and odor intensity enhancement by taste, and generalized mixed effects models (GLMM) with binomial error distributions and logit link functions to analyze odor referral to the oral cavity and tongue.

Model selection began with the maximal random effects structure justified by the design (Barr et al., 2013). If a model failed to converge, we first increased the number of iterations and tried different numerical optimization procedures (Brauer, Curtin, 2018). If the model still did not converge, by-participant random slopes were removed one-by-one, keeping the slope for the effect that was the focus of the confirmatory test for last.

Visual inspection of residual plots (Winter, 2013) indicated that the assumptions of homoscedasticity and normality were not met for odor sweetness due to a high proportion of very low ratings. Hence, to check the robustness of the results of the preregistered gaussian models, we also analyzed the sweetness data using mixedeffects beta regression (MEBR). This method works well for bounded data with high skewness (Smithson \& Verkuilen, 2006). As beta regression is restricted to variables bounded at but not including 1, the single rating of 1 in the sweetness data was replaced with a 0.99 . No other obvious deviations from homoscedasticity or normality were observed.

For odor sweetness, odor intensity enhancement, and odor referral, the main hypothesis was that the effect of session would be stronger on sweet-paired odors than on mere-exposure odors, which would be indicated by a significant interaction term.

For pleasantness, we had two subhypotheses. First, that the pleasantness ratings would increase between the sessions independently of whether the odor had been exposed with or without sucrose during the Exposure Phase. The effect of session was thus expected to be significant (assessed by a model without the interaction term). To compare this effect to potential changes that could have occurred independently of the Exposure Phase, we then used an exploratory paired $t$-test to assess changes in pleasantness (post-exposure ratings vs. pre-exposure ratings) of the retronasal training odorant that only had been presented during the testing sessions. The second sub-hypothesis related to odor pleasantness was that the two-way Session by Condition interaction would vary depending on how much participants liked sweet taste. As previous studies have indicated that odor pleasantness only increases after exposure with sucrose for participants that like sweet taste, we expected a significant Sweet-liking by Session by 
Condition three-way interaction, but no Session by Condition two-way interaction. Moreover, to be able to compare our results to previous findings, an exploratory Pearson correlation analysis was then used to test if changes in pleasantness for sweet-paired odors correlated with sweet-liking.

Equivalence testing was then used to explore the non-significant results from the linear models (Lakens et al., 2018). Two onesided tests were used to assess if the true effects were smaller than what we considered to be the smallest effect size of interest (SESOI). This procedure follows the same logic as null hypothesis significance testing, but instead of testing against zero, equivalence tests are designed to determine whether effects that are large enough to be considered meaningful can be statistically rejected. Because a large number of studies have found positive effects on odor sweetness, SESOI for this outcome was specified based on reported effect sizes in the literature. For the other outcomes where the evidence is less consistent, we decided in advance to test against the effect size that a study with 60 participants had $80 \%$ power to detect. These analyses were not preregistered.
All tests were two-tailed, and the alpha level was set a priori at 0.05 . P-values were obtained by likelihood ratio tests comparing models with and without the effect of interest.

We used R (R core Team, 3.6.3) and R Studio (RStudio Team, 1.2.5033) for all analyses. The statistical packages lme4 (Bates et al., 2015) and glmmTMB (Brooks et al., 2017) were used to fit the mixed effects models, and TOSTER (Lakens, 2017) was used for equivalence testing. Plots were created in ggplot2 (Wickham, 2016) and ggstatsplot (Patil, 2018).

\section{Results}

Baseline ratings of the orthonasal basil and orange flower odorants obtained at the very beginning of the pre-exposure sessions are summarized in Table 1. Descriptive statistics for each outcome variable are displayed in Table 2 and model equations are reported in Table 3. Non-preregistered analyses are labelled as exploratory. Detailed descriptions of the models and the model selection process are provided in the Supplementary material, and on https://osf.io/dtv8s/, together with the results from the secondary analyses specified in the preregistration.

Table 1. Baseline ratings of the orthonasal odorants. Each point estimate is based on 60 ratings. Odor familiarity, odor sweetness, and odor saltiness were assessed by using three separate scales with "Not familiar/sweet/salty at all" $(0.01)$ and "Extremely familiar/sweet/salty" (1) as endpoint anchors. $M=$ mean, $S D=$ standard deviation.

\begin{tabular}{llll}
\hline Odor quality & Familiarity $-\boldsymbol{M}(\boldsymbol{S D})$ & Sweetness $-\boldsymbol{M}(\boldsymbol{S D})$ & Saltiness $-\boldsymbol{M ( S D )}$ \\
\hline Basil & $0.454(0.277)$ & $0.393(0.235)$ & $0.378(0.265)$ \\
Orange flower & $0.551(0.283)$ & $0.460(0.267)$ & $0.214(0.208)$ \\
\hline
\end{tabular}


Table 2. Summary statistics of all outcome variables. $S D=$ standard deviation, $N=$ total number of observations, Count=number of trials where the odor was localized to the oral cavity or tongue.

\begin{tabular}{|c|c|c|c|c|c|c|}
\hline & \multicolumn{3}{|l|}{ Pre-exposure } & \multicolumn{3}{|l|}{ Post-exposure } \\
\hline & Mean (Median) & $S D$ & $N$ & Mean (Median) & $S D$ & $N$ \\
\hline \multicolumn{7}{|l|}{ Odor sweetness } \\
\hline Mere-exposure odors & $0.408(0.465)$ & 0.253 & 60 & $0.400(0.430)$ & 0.245 & 60 \\
\hline Sweet-paired odors & $0.445(0.485)$ & 0.253 & 60 & $0.481(0.505)$ & 0.244 & 60 \\
\hline \multicolumn{7}{|l|}{ Odor pleasantness } \\
\hline Mere-exposure odors & $0.391(0.392)$ & 0.191 & 120 & $0.420(0.433)$ & 0.200 & 120 \\
\hline Sweet-paired odors & $0.404(0.410)$ & 0.203 & 120 & $0.460(0.473)$ & 0.173 & 120 \\
\hline \multicolumn{7}{|l|}{ Odor intensity enhancement } \\
\hline Mere-exposure odors & $2.843(1.722)$ & 13.516 & 120 & $2.092(2.257)$ & 12.357 & 120 \\
\hline Sweet-paired odors & $3.388(1.377)$ & 15.728 & 120 & $3.822(2.431)$ & 11.150 & 120 \\
\hline & \multicolumn{3}{|l|}{ Pre-exposure } & \multicolumn{3}{|l|}{ Post-exposure } \\
\hline Odor referral & Count & & $N$ & Count & & $N$ \\
\hline \multicolumn{7}{|l|}{ Referral to oral cavity } \\
\hline Mere-exposure odors $(\mathrm{n}=120)$ & 89 & & 120 & 99 & & 120 \\
\hline Sweet-paired odors $(\mathrm{n}=120)$ & 91 & & 120 & 91 & & 120 \\
\hline \multicolumn{7}{|l|}{ Referral to tongue } \\
\hline Mere-exposure odors $(\mathrm{n}=120)$ & 61 & & 120 & 58 & & 120 \\
\hline Sweet-paired odors $(n=120)$ & 56 & & 120 & 62 & & 120 \\
\hline
\end{tabular}

Hypothesis 1. Orthonasal odor sweetness (Figure 2A)

We first tested whether perceived odor sweetness increased more between the testing sessions after exposure with a sweet taste, than after exposure without taste. Contrary to expectation, we found no such effect ("Sweetness1" in Table 3, Session x Condition: $\quad b=0.044, \quad 95 \% \quad \mathrm{CI}=[-0.045$, $\left.0.132], \quad \chi^{2}(1)=0.935, \quad p=.334\right) . \quad$ The exploratory MEBR used to assess robustness confirmed this result $\left(\chi^{2}(1)=0.963, p=.326\right)$. Thus, these analyses provided no evidence that the sweetness of sweet-paired odors increased more than the sweetness of mereexposure odors.

This contrasts with previous studies that have reported large changes in odor sweetness after exposure with sucrose, typically corresponding to a $10-25 \%$ increase of the total rating scale. To determine whether our results deviated significantly from these prior findings, we used an equivalence test to compare our observed change (sweetness of sweet-paired odors at post - sweetness of sweet-paired odors at pre) against an equivalence bound of $+/-0.1$ (or $+/-10 \%$ of our rating scale, which corresponded to a Cohen's $d$ of $\sim 0.5$ ). This exploratory test was significant (mean diff $=0.036,90 \%$ CI $[-0.007,0.079]$; Upper bound $-t(59)=-2.471, p=.008$; Lower bound $-t(59)=5.291, p<.001)$, indicating that the effect of sweet pairing on perceived odor sweetness was either absent or significantly smaller than in previous studies. We then assessed main effects in a model without the interaction term. This analysis did not reveal any significant changes between the pre-exposure and postexposure sessions ("Sweetness2" in Table 3, Session: $b=0.015,95 \% \mathrm{CI}=[-0.023,0.052]$, $\left.\chi^{2}(1)=0.599, p=.439\right)$, or between sweetpaired and mere-exposure odors (Condition: $b=0.059,95 \% \quad \mathrm{CI}=[-0.000,0.118], \chi^{2}(1)=$ $3.817, p=.051)$. The results were similar in the exploratory MEBR analysis used to check robustness (Session: $\chi^{2}(1)=1.210, p=.271$; Condition: $\left.\chi^{2}(1)=4.747, p=.029\right)$ but here, 
the effect of Condition reached significance. This reflects that in our sample, participants rated the sweet-paired odor as slightly sweeter than the mere-exposure odor across both testing sessions. This difference was, however, small in comparison to the standard deviation. Importantly, as shown in Figure $2 \mathrm{~A}$, the rating distributions were centered in the middle of the scale and no ceiling effects were present. This means that within both conditions, a potential increase in odor sweetness between the sessions would have been reflected in the actual ratings. Hence, the observed difference in sweetness between sweet-paired and mere-exposure odors likely did not impair our ability to detect any effects of interest.
A
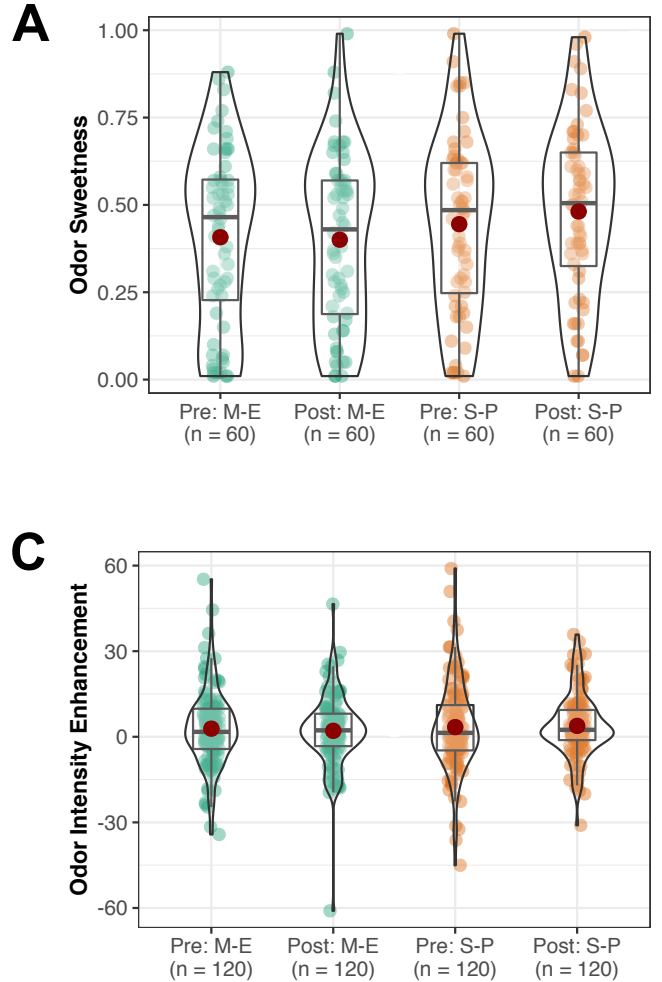

B

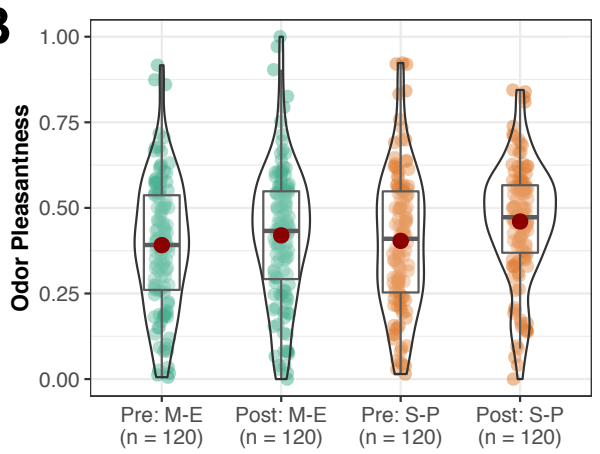

D

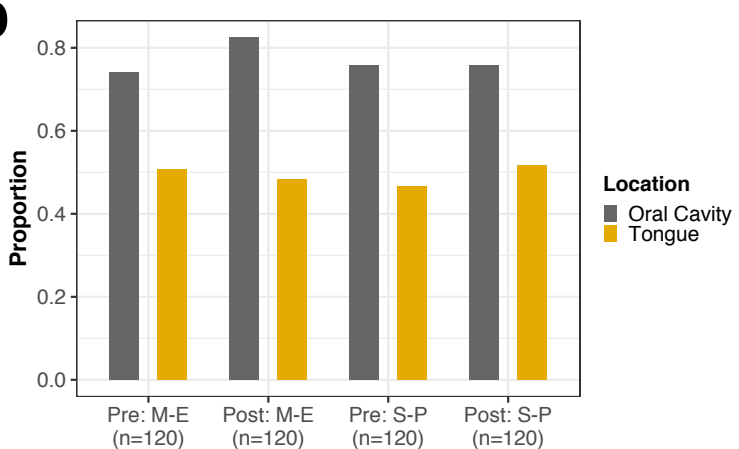

Figure 2. This figure display the distribution of the outcome variables within each Session ("Pre"-exposure vs "Post"-exposure) by Condition ("M-E"=mere-exposure odor vs "S-P"=sweet-paired odor) context. $\mathrm{n}$ is the number of observations per context. In boxplot A-C, the central horizontal lines represent medians and the dark red points represent means. (A) Perceived orthonasal odor sweetness, $0.01=$ "Not sweet at all", 1= "Extremely sweet". (B) Perceived retronasal odor pleasantness, $0.01=$ "Not pleasant at all", 1= "Very pleasant". (C) Odor intensity enhancement by taste. This score was obtained by subtracting the intensity rating for each odor solution, e.g. a solution with only the basil odorant, from the respective intensity rating of the same odor solution when it also contained sucrose, e.g. a solution with both basil odorant and sucrose. The raw intensity ratings were on a scale from 1="Barely detectable" to 100="Strongest imaginable". (D) Odor referral to the mouth. Proportion of trials where the participants localized the odor component of the odor-sucrose solutions to the oral cavity and tongue, respectively.

\section{Hypothesis 2. Retronasal odor pleasantness (Figure 2B)}

We then tested if pleasantness ratings increased between the sessions, independently of whether the odor had been exposed with or without sucrose during the
Exposure Phase. A significant main effect of Session supported this hypothesis ("Pleasantness1" in Table 3, $b=0.039,95 \%$ $\left.\mathrm{CI}=[0.009,0.070], \chi^{2}(1)=6.244, p=.012\right)$. As expected, this model provided no evidence that pleasantness differed between the sweet- 
paired and mere-exposure odors (Condition: $b=0.034, \quad 95 \% \quad \mathrm{CI}=[-0.003, \quad 0.070]$, $\left.\chi^{2}(1)=3.343, p=.067\right)$.

The significant increase between the sessions could have been due to the repeated presentations during the Exposure Phase, or to effects associated with multiple testing. To explore the latter possibility, we then used an exploratory paired $t$-test to compare ratings (pre-exposure vs. post-exposure) of the retronasal training odor that only had been presented during the testing sessions. The difference was not significant (mean diff $=$ $0.030,95 \% \mathrm{CI}=[-0.001,0.060], t(59)=1.953$, $p=.056$ ), but the observed increase was similar in magnitude to the increase among the target basil and orange flower odorants.

In line with our hypothesis, a subsequent model ("Pleasantness2" in Table 3) that also included the interaction term did not support the notion that changes in pleasantness varied depending on whether the odor had been presented with or without sweet taste during the Exposure Phase (Session x Condition: $b=0.028,95 \% \mathrm{CI}=[-$ $\left.0.016,0.072], \chi^{2}(1)=1.598, p=.206\right)$. The reason why we did not expect the increase between the sessions to vary between sweetpaired and mere-exposure odors is that not all people like sweet taste. Instead, we hypothesized that the (non-significant) interaction would be modulated by the degree to which participants liked sweet taste. A model that also included a Session by Condition by Sweet-liking interaction did not, however, support this notion ("Pleasantness3" in Table 3, Session $x$ Condition x Sweet-liking: $b=-0.001,95 \%$ $\left.\mathrm{CI}=[-0.003,0.002], \chi^{2}(1)=0.291, p=.589\right)$. To further explore the role of sweet-liking in the development of odor pleasantness, an exploratory Pearson correlation analysis was used to test if changes in pleasantness for sweet-paired odors correlated with sweet- liking. To do so, ratings of identical stimuli within each session were first averaged. We then calculated changes in pleasantness for sweet-paired odors by subtracting preexposure scores from post-exposure scores. Next, these difference scores were correlated with sweet-liking to test if changes in liking of sweet-paired odors were linearly associated with the degree to which participants liked sweet taste. In line with our previous result, the correlation coefficient was not significant $(r(58)=-.153,95 \% \mathrm{CI}=[-$ $.391, .105], p=.245)$. Last, results from an exploratory equivalence test showed that the correlation was indeed significantly smaller than the upper equivalence bound of $r=+.353$ (90\% CI [-.355, .064], $p<.001)$, but not significantly bigger than -.353 $(p=.053)$. Taken together, these results suggest that given our experimental set-up, the potential positive correlation between sweet-liking and changes in pleasantness was, at best, weak.

Hypothesis 3. Retronasal odor intensity enhancement (Figure 2C)

We then tested if changes between the sessions in odor intensity enhancement by taste differed between sweet-paired and mere-exposure odors. The non-significant Session by Condition interaction did not support this notion ("Intensity1" in Table 3, $b=1.185, \quad 95 \% \quad \mathrm{CI}=[-3.215, \quad 5.584]$, $\left.\chi^{2}(1)=0.281, \quad p=.596\right)$. An exploratory equivalence test was then used to assess if changes in odor intensity enhancement between the sessions for sweet-paired odors were reliably smaller than $\pm d=0.368$ (= \pm 3.682 on the original 1:100 scale). Both tests were significant (mean diff $=0.434$, $90 \% \mathrm{CI}=[-1.726,2.594]$; Upper bound $-t(59)$ $=-2.513, p=.007$; Lower bound $t(59)=3.184, \quad p=.001), \quad$ suggesting that 
medium sized effects could be statistically rejected.

As expected, the next model ("Intensity2" in Table 3) that did not include the interaction term provided no evidence that odor intensity enhancement differed between the pre-exposure and post -exposure sessions (Session: $b=-0.159,95 \% \quad \mathrm{CI}=[-$ $\left.2.282,1.965], \chi^{2}(1)=0.022, p=.883\right)$, or between the sweet-paired and mere-exposure odors (Condition: $b=1.138,95 \% \mathrm{CI}=[-1.428$, 3.703], $\left.\chi^{2}(1)=0.775, p=.379\right)$.

Hypothesis 4. Odor referral to the oral cavity and tongue (Figure 2D)

Finally, two models ("OdorReferral_OC1" and "OdorReferral_T1" in Table 3) were used to test if changes in odor referral to any of the anatomical location in the mouth differed between sweet-paired and mere- exposure odors. Our results did not support this notion as both Session by Condition interactions were non-significant (Oral cavity: $b=-0.611,95 \% \mathrm{CI}=[-2.048,0.744]$, $\chi^{2}(1)=0.821, p=.365$; Tongue: $b=0.428,95 \%$ $\left.\mathrm{CI}=[-0.440,1.305], \chi^{2}(1)=0.940, p=.332\right)$.

As expected, odor referral to the mouth did not vary significantly between the sessions (oral cavity ["OdorReferral_OC2" in Table 3]: $b=0.238,95 \% \quad \mathrm{CI}=[-0.457$, $0.947], \quad \chi^{2}(1)=0.487, \quad p=.485 ; \quad$ tongue ["OdorReferral_T2" in Table 3]: $b=0.083$, $95 \% \quad \mathrm{CI}=[-0.483, \quad 0.658], \quad \chi^{2}(1)=0.087$, $p=.768$ ) or between mere-exposure odors and sweet-paired odors (oral cavity ["OdorReferral_OC3" in Table 3]: $b=-$ $0.276,95 \% \mathrm{CI}=[-0.990,0.375], \chi^{2}(1)=0.710$, $p=.399$; tongue ["OdorReferral_T2" in Table $3]: \quad b=-0.030, \quad 95 \% \quad \mathrm{CI}=[-0.506,0.442]$, $\left.\chi^{2}(1)=0.016, p=.899\right)$.

Table 3. Model equations corresponding to each primary hypothesis. LMM=linear mixed effect model, GLMM= generalized mixed effects model with binomial error distribution and a logit link function, $\beta=$ fixed effects, $\mu=$ random effects, $\varepsilon=$ residual.

\begin{tabular}{|c|c|}
\hline $\begin{array}{l}\text { Model name } \\
\text { (model type) }\end{array}$ & Equation \\
\hline $\begin{array}{l}\text { Sweetness } 1 \\
\text { (LMM) }\end{array}$ & $\begin{array}{l}\text { Sweetness }=\beta_{0}+\beta_{1} * \text { Session }+\beta_{2} * \text { Condition }+\beta_{3} * \text { Session } * \text { Condition }+\mu_{0}+\mu_{1} * \text { Session } * \\
\text { Condition }+\varepsilon\end{array}$ \\
\hline $\begin{array}{l}\text { Sweetness } 2 \\
\text { (LMM) }\end{array}$ & Sweetness $=\beta_{0}+\beta_{1} *$ Session $+\beta_{2} *$ Condition $+\mu_{0}+\mu_{1} *$ Session $+\mu_{2} *$ Condition $+\varepsilon$ \\
\hline $\begin{array}{l}\text { Pleasantness1 } \\
(\text { LMM) }\end{array}$ & $\begin{array}{l}\text { Pleasantness }=\beta_{0}+\beta_{1} * \text { Session }+\beta_{2} * \text { Condition }+\mu_{0}+\mu_{1} * \text { Session }+\mu_{2} * \text { Condition }+\mu_{3} * \\
\text { Session } * \text { Condition }+\varepsilon\end{array}$ \\
\hline $\begin{array}{l}\text { Pleasantness2 } \\
\text { (LMM) }\end{array}$ & $\begin{array}{l}\text { Pleasantness }=\beta_{0}+\beta_{1} * \text { Session }+\beta_{2} * \text { Condition }+\beta_{3} * \text { Session } * \text { Condition }+\mu_{0}+\mu_{1} * \text { Session }+ \\
\mu_{2} * \text { Condition }+\mu_{3} * \text { Session } * \text { Condition }+\varepsilon\end{array}$ \\
\hline $\begin{array}{l}\text { Pleasantness } 3 \\
\text { (LMM) }\end{array}$ & $\begin{array}{l}\text { Pleasantness }=\beta_{0}+\beta_{1} * \text { Session }+\beta_{2} * \text { Condition }+\beta_{3} * \text { SweetPreference }+\beta_{4} * \text { Session } * \\
\text { Condition }+\beta_{5} * \text { Session } * \text { SweetPreference }+\beta_{6} * \text { Condition } * \text { SweetPreference }+\beta_{7} * \text { Session } * \\
\text { Condition } * \text { SweetPreference }+\mu_{0}+\mu_{1} * \text { Session }+\mu_{2} * \text { Condition }+\mu_{3} * \text { Session } * \text { Condition }+\varepsilon\end{array}$ \\
\hline $\begin{array}{l}\text { Intensity } 1 \\
\text { (LMM) }\end{array}$ & $\begin{array}{l}\text { Intensity Enhancement }=\beta_{0}+\beta_{1} * \text { Session }+\beta_{2} * \text { Condition }+\beta_{3} * \text { Session } * \text { Condition }+\mu_{0}+\mu_{1} * \\
\text { Session } * \text { Condition }+\varepsilon\end{array}$ \\
\hline $\begin{array}{l}\text { Intensity } 2 \\
\text { (LMM) }\end{array}$ & $\begin{array}{l}\text { Intensity Enhancement }=\beta_{0}+\beta_{1} * \text { Session }+\beta_{2} * \text { Condition }+\mu_{0}+\mu_{1} * \text { Session }+\mu_{2} * \text { Condition }+ \\
\text { - }\end{array}$ \\
\hline $\begin{array}{l}\text { OdorReferral_OC1 } \\
\text { (GLMM) }\end{array}$ & $\begin{array}{l}\text { Oral Cavity, Logit }(\text { Odds })=\beta_{0}+\beta_{1} * \text { Session }+\beta_{2} * \text { Condition }+\beta_{3} * \text { Session } * \text { Condition }+\mu_{0}+ \\
\mu_{1} * \text { Session } * \text { Condition }+\varepsilon\end{array}$ \\
\hline $\begin{array}{l}\text { OdorReferral_T1 } \\
\text { (GLMM) }\end{array}$ & $\begin{array}{l}\text { Tongue, Logit }(\text { Odds })=\beta_{0}+\beta_{1} * \text { Session }+\beta_{2} * \text { Condition }+\beta_{3} * \text { Session } * \text { Condition }+\mu_{0}+\mu_{1} * \\
\text { Session } * \text { Condition }+\varepsilon\end{array}$ \\
\hline $\begin{array}{l}\text { OdorReferral_OC2 } \\
\text { (GLMM) }\end{array}$ & Oral Cavity, Logit $($ Odds $)=\beta_{0}+\beta_{1} *$ Session $+\beta_{2} *$ Condition $+\mu_{0}+\mu_{1} *$ Session $+\varepsilon$ \\
\hline $\begin{array}{l}\text { OdorReferral_OC3 } \\
\text { (GLMM) }\end{array}$ & Oral Cavity, Logit $($ Odds $)=\beta_{0}+\beta_{1} *$ Session $+\beta_{2} *$ Condition $+\mu_{0}+\mu_{1} *$ Condition $+\varepsilon$ \\
\hline $\begin{array}{l}\text { OdorReferral_T2 } \\
\text { (GLMM) }\end{array}$ & Tongue, Logit $($ Odds $)=\beta_{0}+\beta_{1} *$ Session $+\beta_{2} *$ Condition $+\mu_{0}+\mu_{1} *$ Session $+\mu_{2} *$ Condition $+\varepsilon$ \\
\hline
\end{tabular}




\section{Discussion}

The aim of this study was to explore the potential role of associative learning in naturalistic odor-taste interactions. We used several outcome measures to cover different aspects of the food selection and ingestion process, all of which have previously been suggested to be modulated by learning. Although our exposure protocol was extensive and the sample size large compared to previous studies, we found no evidence of associative learning effects on any of the outcomes. Moreover, the presence of medium-sized effects was statistically rejected through exploratory equivalence tests, indicating that with the described method, effects of associative learning within the olfactory-gustatory network are either absent or small in magnitude.

In line with our hypothesis, both target odorants were rated as more pleasant at the post-exposure session than at the preexposure session. This increase might be explained by mere-exposure effects. The role of mere-exposure for the development of odor preferences has been suggested by previous studies that found positive correlations between pleasantness and familiarity (e.g. Distel et al., 1999). This idea also fits well into the broader psychological learning literature where mere-exposure effects have been documented for many types of auditory and visual stimuli (e.g. Montoya et al., 2017). It is important to note, however, that a numerically similar, albeit nonsignificant, increase was also observed for the citrus-like training odor, which was only presented during the testing sessions and not during the Exposure Phase. As such, we cannot conclusively attribute the increased pleasantness of the two target odors to repeated exposure between the sessions. It is, however, possible that the single exposure at baseline was sufficient to trigger a mereexposure effect in all three odorants. Apparent effects on odor sweetness have previously been reported in flavor learning paradigms that contained only two exposure sessions (Stevenson et al., 2000a). One argument against this explanation is that the training odorant was, unlike the basil and orange flower odorants, easy to identify. Most participants correctly labeled it as "citrus", "lemon", or "lemon candy". While there is no experimental evidence that odors need to be novel in order to be affected by exposure, one can speculate that it might take more than a single exposure to alter the hedonic dimension of odors that have been so firmly encoded in memory that they are identifiable even without verbal cues. In line with this reasoning, previous studies on flavor learning have, just like the present study, selected target odors that are not highly familiar (e.g. Stevenson et al., 1995). Follow-up studies are needed to further explore mere-exposure effects on odor pleasantness and the potential role of novelty in this process.

We found no evidence that the observed increase in pleasantness was amplified by sweet-pairing across all participants. This was expected given, as outlined in the introduction, the heterogeneity of results from previous studies. While the notion that sweet-pairing might have amplifying effects on odor pleasantness is firmly grounded in learning theory and rests on the principles of Pavlovian conditioning (De Houwer et al., 2001), a central assumption is that sweet taste is actually perceived as rewarding. For individuals that do not like sweet taste, there is no reason to believe that repeated exposure to odor-sucrose mixtures would make the odors more pleasant. High interindividual variability in sweet-liking has therefore been 
proposed to explain the heterogeneity of previous results (Yeomans et al., 2006). Contrary to expectation, our study did not support the notion that sweet-liking modulates the amplifying effect of sweetpairing on odor pleasantness. In subsequent exploratory analyses, we tested whether sweet-liking and the increase in pleasantness of sweet-paired odors were positively correlated. We found no evidence for such a relationship and a subsequent equivalence test confirmed that the hypothesized positive correlation was indeed weak at most. Taken together, our study did not provide any support for the proposed effect of associative learning on perceived odor pleasantness.

Previous studies have shown that perceived odor intensity can be enhanced by taste, but only if the odor-taste combination is familiar (Green et al., 2012). Green and colleagues (2012) speculated that this effect might serve to enhance the salience of familiar nutritious foods. Given that odors provide the unique sensory profile necessary for object identification, while taste provide information about macronutrient content, is seems likely that the function of odor enhancement by sweet taste is to strengthen the associative link between the food object and its nutritive value. To the best of our knowledge, this study was the first to directly test whether such effects on perceived odor intensity can be experimentally induced through exposure with sucrose. We found no evidence that this was the case, as the (nonsignificant) increase in odor enhancement by taste between the sessions did not vary depending on whether the odor had been presented with or without sucrose during the Exposure Phase. Results from an exploratory equivalence test further revealed that changes in odor intensity enhancement for sweetpaired odors were either absent or small in magnitude. Future studies assessing the potential effect of associative learning on odor intensity should consider that even if the effect exists, it likely needs a powerful experimental set-up to be detectable.

We found no evidence that odor referral to the mouth varied depending on whether the odor had been presented with or without sucrose during the Exposure Phase. It has been known for over a century that, although the olfactory receptors are located in the nasal cavity, people frequently perceive the odor component of flavor in the mouth (Hollingworth \& Poffenberger Jr., 1917). This illusion has been interpreted as a demonstration of the ability of odors and tastes to create unified flavor percepts (Stevenson, 2014), and has been suggested to be the reason why people erroneously attribute olfactory content to the gustatory modality (vanilla yoghurt is said to taste, not smell, like vanilla). Previous studies have shown that the perceived location of retronasal odors shifts towards the mouth when presented together with taste, but only if the odor-taste combination is familiar (e.g. Lim \& Johnson, 2011). The reliance on familiarity suggests that associative learning might play a role in creating this illusion. Our non-significant results add to the literature by suggesting that if odor referral is modulated by how often the odor and taste have been perceived together in the past, this effect might only arise during specific experimental conditions which need to be specified further.

Last, we expected that perceived odor sweetness would increase more after exposure with sucrose than after exposure without taste. This hypothesis was not supported. Moreover, an exploratory equivalence test further suggested that the increase in odor sweetness corresponded to significantly less than $10 \%$ of our rating scale. This indicates that associative learning effects on perceived odor sweetness were, for 
our experimental setup, weak at most. These results are inconsistent with past studies that in general have reported large effects of exposure with sucrose on perceived odor sweetness (Prescott et al., 2004; Prescott \& Murphy, 2009; Privitera et al., 2012; Stevenson et al., 1995, 1998, 2000a, 2000b; Stevenson \& Case, 2003; Stevenson \& Mahmut, 2011a, 2011b; Yeomans et al., 2009; Yeomans \& Boakes, 2016). One possibility is that this discrepancy is related to differences in stimulus material. While we carefully piloted the target odors to ensure that they satisfied both the sensory (e.g. tasteless, clearly perceivable but not unpleasantly strong, moderately pleasant) and semantic (moderately familiar but not identifiable) requirements that have been suggested to facilitate odor-taste interactions, the basil and orange flower odorants have never been used in an exposure program before. We cannot rule out that these odors might have been more resistant to sweetpairing than the odors that have been used previously. To formally assess the generalizability of the effect of sweet-pairing on odor sweetness, a broader stimulus set would be needed with a large number of target odorants. Such an approach would allow for statistical evaluation of betweenodorant variability in the same way as testing multiple participants several times allows for evaluation of between-participant variability when making inferences at the population level (Yarkoni, 2019). Given that such a diversity of stimulus material would require extensive and prolonged investments from any individual research group, coordinated efforts to promote team science would be highly desirable.

In addition to relying on a very small number of previously untested target odors, another possible limitation of our study is that we used chewing gums to present the stimulus material between the sessions. Previous studies have used liquids with dissolved odorants and tastants both for testing and exposure. The advantage of this latter method is consistency and control, the disadvantage is that the amount of exposure will be limited as the participants will need to visit the lab for each odor-taste presentation. By using chewing gums instead of liquids, our participants could be exposed to the odors multiple times every day without having to visit the lab. Although all participants were in daily contact with the experiment leader to ensure that all gums had actually been chewed, we cannot rule out that this setup was less effective than if the stimuli had been presented in liquid form and administered in the lab. While such an approach would have limited the number of stimulus presentations, it would have resulted in better control over the presentations and eliminated the need for generalization of potential learning effects across presentation modes (chewing gums during exposure, liquids during testing).

One final possible explanation for the lack of increase in odor sweetness is that associative learning effects might be weaker than previous studies have suggested. In that case, our sample size would not have been large enough to detect the true effect. This explanation would be consistent with large scale replication studies from other sub-fields within psychology, which on average have produced effect sizes that are about half as strong as those reported in the original studies (Camerer et al., 2018; Klein et al., 2018; Open Science Collaboration, 2015). Based on everyday eating experience, small effects seem indeed plausible: the observation that many odors that exclusively appear in desserts (e.g. vanilla) have sweet smells clearly suggests that repeated exposure with taste can alter how the odor is 
subsequent processed. Yet, while most would probably agree that vanilla smells sweet, we seldomly experience that odor sweetness changes noticeably through a few exposures. In fact, many non-sweet food odors, such as chicken, do regularly appear together with sweet taste (e.g. honey roasted chicken) without becoming sweet-smelling. While our study thus does not challenge the validity of previous work due to the methodological discrepancies mentioned above, a preregistered and independent direct replication of a prior study that has reported a large effect would be highly informative. Such a study would be useful to confirm that associative learning reliably can affect odor sweetness under specific conditions. Also, it would act as a stepping stone for more systematic investigations of the types of exposure programs that are best suited to detect the potential effect.

In conclusion, the aim of this study was to disentangle associative learning effects from mere-exposure effects on four foodrelevant outcomes that have been suggested to rely on past experience: odor sweetness, odor pleasantness, odor intensity enhancement by taste, and odor referral to the mouth. Our hypotheses were assessed using a large sample compared to other studies in the field and data was analyzed according to a preregistered analysis plan. Contrary to expectation, our results did not provide any evidence for associative learning effects on any of the outcomes. To our best knowledge, this is the first time that odor intensity enhancement by taste and odor referral to the mouth has been assessed in an exposurebased learning study. Moreover, as previous attempts to amplify odor pleasantness by exposure with sucrose have yielded heterogeneous results, the absence of associative learning effects on pleasantness in our study does not deviate much from the existing literature. Future studies should consider the possibility that if these three phenomena rely on associative learning, the effects might be fragile and not so easy to induce experimentally. However, our observed null effect on odor sweetness does contrast with several previous reports. This discrepancy might indicate that the acquisition of learned associations between odor and taste during food consumption are dependent on the context that the exposure takes place in, or that some odors might be more resistant to sweet-pairing than others. Alternatively, the observed lack of increase in odor sweetness might indicate that the true effect is smaller than previously thought. High-powered direct replications of studies that have reported changes in odor sweetness would be highly informative to assess the reliability of this effect. If such studies would confirm previous findings, further exploration of potential influencing factors and a conscious effort to create comparable setups between different research groups would be desirable to increase our understanding of the specific conditions under which such effects occur. Taken together, these efforts will have the potential to transform our understanding of how food perception and eating behavior develop over time, and thus provide important insights into the perceptual basis of human food choice.

\section{Acknowledgments}

We would like to thank Ida Siemens Lorenzen and Cristina Rossi for their invaluable assistance in the lab.

This work was funded by grants from the Swedish Research Council (VR 201801305 awarded to JS), the Knut and Alice Wallenberg Foundation (KAW 2018.0152 awarded to JNL), and the Karolinska Institutet (CSTP awarded to RF and JS). 


\section{References}

Baeyens, F., Crombez, G., De Houwer, J., \& Eelen, P. (1996). No Evidence for Modulation of Evaluative Flavor-Flavor Associations in Humans. Learning and Motivation, 27(2), 200-241. https://doi.org/10.1006/lmot.1996.0012

Baeyens, F., Crombez, G., Hendrickx, H., \& Eelen, P. (1995). Parameters of human evaluative flavor-flavor conditioning. Learning and Motivation, 26(2), 141-160. https://doi.org/10.1016/0023-9690(95)90002-0

Baeyens, F., Eelen, P., Van den Bergh, O., \& Crombez, G. (1990). Flavor-flavor and colorflavor conditioning in humans. Learning and Motivation, 21(4), 434-455. https://doi.org/10.1016/0023-9690(90)90025-J

Barkat, S., Poncelet, J., Landis, B. N., Rouby, C., \& Bensafi, M. (2008). Improved smell pleasantness after odor-taste associative learning in humans. Neuroscience Letters, 434(1), 108-112. https://doi.org/10.1016/j.neulet.2008.01.037

Bates, D., Mächler, M., Bolker, B., \& Walker, S. (2015). Fitting Linear Mixed-Effects Models Using lme4. Journal of Statistical Software, 67(1), 1-48. https://doi.org/10.18637/jss.v067.i01

Bornstein, R. F. (1989). Exposure and affect: Overview and meta-analysis of research, 19681987. Psychological Bulletin, 106(2), 265-289. https://doi.org/10.1037/00332909.106.2.265

Brooks, M. E., Kristensen, K., Benthem, K. J. van, Magnusson, A., Berg, C. W., Nielsen, A., Skaug, H. J., Mächler, M., \& Bolker, B. M. (2017). GlmmTMB Balances Speed and Flexibility Among Packages for Zero-inflated Generalized Linear Mixed Modeling. The R Journal, 9(2), 378-400. https://doi.org/10.32614/RJ-2017-066

Camerer, C. F., Dreber, A., Holzmeister, F., Ho, T.-H., Huber, J., Johannesson, M., Kirchler, M., Nave, G., Nosek, B. A., Pfeiffer, T., Altmejd, A., Buttrick, N., Chan, T., Chen, Y., Forsell, E., Gampa, A., Heikensten, E., Hummer, L., Imai, T., ... Wu, H. (2018). Evaluating the replicability of social science experiments in Nature and Science between 2010 and 2015. Nature Human Behaviour, 2(9), 637-644. https://doi.org/10.1038/s41562-018-0399-z

De Houwer, J., Thomas, S., \& Baeyens, F. (2001). Associative learning of likes and dislikes: A review of 25 years of research on human evaluative conditioning. Psychological Bulletin, 127(6), 853-869. https://doi.org/10.1037/0033-2909.127.6.853

Dickinson, A., \& Brown, K. J. (2007). Flavor-evaluative conditioning is unaffected by contingency knowledge during training with color-flavor compounds. Animal Learning \& Behavior, 35(1), 36-42. https://doi.org/10.3758/BF03196072

Distel, H., Ayabe-Kanamura, S., Martínez-Gómez, M., Schicker, I., Kobayakawa, T., Saito, S., \& Hudson, R. (1999). Perception of everyday odors - Correlation between intensity, familiarity and strength of hedonic judgement. Chemical Senses, 24(2), 191-199. https://doi.org/10.1093/chemse/24.2.191

Doty, R. L. (Ed.). (2019). Smell and Taste (1 edition). In Handbook of Clinical Neurology (Vol. 164). Elsevier.

Dravnieks, A. (1985). Atlas of odor character profiles. American Society for Testing of Material. 
Fondberg, R., Lundström, J. N., Blöchl, M., Olsson, M. J., \& Seubert, J. (2018). Multisensory flavor perception: The relationship between congruency, pleasantness, and odor referral to the mouth. Appetite, 125, 244-252. https://doi.org/10.1016/j.appet.2018.02.012

Fujimaru, T., \& Lim, J. (2013). Effects of Stimulus Intensity on Odor Enhancement by Taste. Chemosensory Perception, 6(1), 1-7. https://doi.org/10.1007/s12078-013-9140-5

Green, B. G., Nachtigal, D., Hammond, S., \& Lim, J. (2012). Enhancement of retronasal odors by taste. Chemical Senses, 37(1), 77-86. https://doi.org/10.1093/chemse/bjr068

Hollingworth, H. L., \& Poffenberger Jr., A. T. (1917). The sense of taste. Moffat \& Yard. https://doi.org/10.1037/10825-000

Iatridi, V., Hayes, J. E., \& Yeomans, M. R. (2019). Quantifying Sweet Taste Liker Phenotypes: Time for Some Consistency in the Classification Criteria. Nutrients, 11(1), 129. https://doi.org/10.3390/nu11010129

Kim, J.-Y., Prescott, J., \& Kim, K.-O. (2017). Emotional responses to sweet foods according to sweet liker status. Food Quality and Preference, 59, 1-7. https://doi.org/10.1016/j.foodqual.2017.01.013

Klein, R. A., Vianello, M., Hasselman, F., Adams, B. G., Adams, R. B., Alper, S., Aveyard, M., Axt, J. R., Babalola, M. T., Bahník, Š., Batra, R., Berkics, M., Bernstein, M. J., Berry, D. R., Bialobrzeska, O., Binan, E. D., Bocian, K., Brandt, M. J., Busching, R., ... Nosek, B. A. (2018). Many Labs 2: Investigating Variation in Replicability Across Samples and Settings. Advances in Methods and Practices in Psychological Science, 1(4), 443-490. https://doi.org/10.1177/2515245918810225

Labbe, D., \& Martin, N. (2009). Impact of Novel Olfactory Stimuli at Supra and Subthreshold Concentrations on the Perceived Sweetness of Sucrose after Associative Learning. Chemical Senses, 34(8), 645-651. https://doi.org/10.1093/chemse/bjp045

Lakens, D. (2017). Equivalence Tests: A Practical Primer for t Tests, Correlations, and MetaAnalyses. Social Psychological and Personality Science, 8(4), 355-362. https://doi.org/10.1177/1948550617697177

Lakens, D., Scheel, A. M., \& Isager, P. M. (2018). Equivalence Testing for Psychological Research: A Tutorial. Advances in Methods and Practices in Psychological Science, 1(2), 259-269. https://doi.org/10.1177/2515245918770963

Lewkowicz, D. J., \& Ghazanfar, A. A. (2009). The emergence of multisensory systems through perceptual narrowing. Trends in Cognitive Sciences, 13(11), 470-478. https://doi.org/10.1016/j.tics.2009.08.004

Lim, J., Fujimaru, T., \& Linscott, T. D. (2014). The role of congruency in taste-odor interactions. Food Quality and Preference, 34, 5-13. https://doi.org/10.1016/j.foodqual.2013.12.002

Lim, J., \& Johnson, M. B. (2011). Potential Mechanisms of Retronasal Odor Referral to the Mouth. Chemical Senses, 36(3), 283-289. https://doi.org/10.1093/chemse/bjq125

Lim, J., \& Johnson, M. B. (2012). The role of congruency in retronasal odor referral to the mouth. Chemical Senses, 37(6), 515-522. https://doi.org/10.1093/chemse/bjs003

Linscott, T. D., \& Lim, J. (2016). Retronasal odor enhancement by salty and umami tastes. Food Quality and Preference, 48, 1-10. https://doi.org/10.1016/j.foodqual.2015.08.004

Montoya, R. M., Horton, R. S., Vevea, J. L., Citkowicz, M., \& Lauber, E. A. (2017). A reexamination of the mere exposure effect: The influence of repeated exposure on 
recognition, familiarity, and liking. Psychological Bulletin, 143(5), 459-498. https://doi.org/10.1037/bul0000085

Mundy, M. E., Dwyer, D. M., \& Honey, R. C. (2006). Inhibitory associations contribute to perceptual learning in humans. Journal of Experimental Psychology: Animal Behavior Processes, 32(2), 178-184. https://doi.org/10.1037/0097-7403.32.2.178

Open Science Collaboration. (2015). Estimating the reproducibility of psychological science. Science, 349(6251). https://doi.org/10.1126/science.aac4716

Patil, I. (2018). ggstatsplot: "ggplot2" Based Plots with Statistical Details. CRAN. https://doi.org/10.5281/zenodo.2074621

Prescott, J. (1999). Flavour as a psychological construct: Implications for perceiving and measuring the sensory qualities of foods. Food Quality and Preference, 10(4), 349-356. https://doi.org/10.1016/S0950-3293(98)00048-2

Prescott, J. (2012). Chemosensory learning and flavour: Perception, preference and intake. Physiology \& Behavior, 107(4), 553-559. https://doi.org/10.1016/j.physbeh.2012.04.008

Prescott, J., Johnstone, V., \& Francis, J. (2004). Odor-taste interactions: Effects of attentional strategies during exposure. Chemical Senses, 29(4), 331-340. https://doi.org/10.1093/chemse/bjh036

Prescott, J., \& Murphy, S. (2009). Inhibition of evaluative and perceptual odour-taste learning by attention to the stimulus elements. Quarterly Journal of Experimental Psychology, 62(11), 2133-2140. https://doi.org/10.1080/17470210903031169

Privitera, G. J., Mulcahey, C. P., \& Orlowski, C. M. (2012). Human sensory preconditioning in a flavor preference paradigm. Appetite, 59(2), 414-418. https://doi.org/10.1016/j.appet.2012.06.005

Rozin, P. (1982). "Taste-smell confusions" and the duality of the olfactory sense. Perception \& Psychophysics, 31(4), 397-401. https://doi.org/10.3758/BF03202667

Ruszpel, B., \& Gast, A. (2020). Memory and preparedness in evaluative conditioning in a smell-taste paradigm. A registered report. Cognition and Emotion, 34(5), 1068-1082. https://doi.org/10.1080/02699931.2020.1719982

Schifferstein, H. N. J., \& Verlegh, P. W. J. (1996). The role of congruency and pleasantness in odor-induced taste enhancement. Acta Psychologica, 94(1), 87-105. https://doi.org/10.1016/0001-6918(95)00040-2

Small, D. M., Voss, J., Mak, Y. E., Simmons, K. B., Parrish, T., \& Gitelman, D. (2004). Experience-Dependent Neural Integration of Taste and Smell in the Human Brain. Journal of Neurophysiology, 92(3), 1892-1903. https://doi.org/10.1152/jn.00050.2004

Smithson, M., \& Verkuilen, J. (2006). A better lemon squeezer? Maximum-likelihood regression with beta-distributed dependent variables. Psychological Methods, 11(1), 5471. https://doi.org/10.1037/1082-989X.11.1.54

Spence, C. (2016). Oral referral: On the mislocalization of odours to the mouth. Food Quality and Preference, 50, 117-128. https://doi.org/10.1016/j.foodqual.2016.02.006

Stevenson, R. J. (2014). Flavor binding: Its nature and cause. Psychological Bulletin, 140(2), 487-510. https://doi.org/10.1037/a0033473

Stevenson, R. J., Boakes, R. A., \& Prescott, J. (1998). Changes in odor sweetness resulting from implicit learning of a simultaneous odor-sweetness association: An example of 
learned synesthesia. Learning and Motivation, 29(2), 113-132.

https://doi.org/10.1006/lmot.1998.0996

Stevenson, R. J., Boakes, R. A., \& Wilson, J. P. (2000a). Resistance to extinction of conditioned odor perceptions: Evaluative conditioning is not unique. Journal of Experimental Psychology. Learning, Memory, and Cognition, 26(2), 423-440. https://doi.org/10.1037//0278-7393.26.2.423

Stevenson, R. J., Boakes, R. A., \& Wilson, J. P. (2000b). Counter-conditioning Following Human Odor-Taste and Color-Taste Learning. Learning and Motivation, 31(2), 114127. https://doi.org/10.1006/lmot.1999.1044

Stevenson, R. J., \& Case, T. I. (2003). Preexposure to the stimulus elements, but not training to detect them, retards human odour-taste learning. Behavioural Processes, 61(1-2), 13-25. https://doi.org/10.1016/s0376-6357(02)00166-3

Stevenson, R. J., \& Mahmut, M. K. (2011a). Experience dependent changes in odourviscosity perception. Acta Psychologica, 136(1), 60-66. https://doi.org/10.1016/j.actpsy.2010.10.001

Stevenson, R. J., \& Mahmut, M. K. (2011b). Discriminating the stimulus elements during human odor-taste learning: A successful analytic stance does not eliminate learning. Journal of Experimental Psychology. Animal Behavior Processes, 37(4), 477-482. https://doi.org/10.1037/a0023430

Stevenson, R. J., Mahmut, M. K., \& Oaten, M. J. (2011). The role of attention in the localization of odors to the mouth. Attention, Perception \& Psychophysics, 73(1), 247258. https://doi.org/10.3758/s13414-010-0013-6

Stevenson, R. J., \& Oaten, M. J. (2010). Sweet odours and sweet tastes are conflated in memory. Acta Psychologica, 134(1), 105-109. https://doi.org/10.1016/j.actpsy.2010.01.001

Stevenson, R. J., Prescott, J., \& Boakes, R. A. (1995). The acquisition of taste properties by odors. Learning and Motivation, 26(4), 433-455. https://doi.org/10.1016/S00239690(05)80006-2

Sundqvist, N. C., Stevenson, R. J., \& Bishop, I. R. J. (2006). Can odours acquire fat-like properties? Appetite, 47(1), 91-99. https://doi.org/10.1016/j.appet.2006.03.328

van den Bosch, I., van Delft, J. M., de Wijk, R. A., de Graaf, C., \& Boesveldt, S. (2015). Learning to (dis)like: The effect of evaluative conditioning with tastes and faces on odor valence assessed by implicit and explicit measurements. Physiology \& Behavior, 151, 478-484. https://doi.org/10.1016/j.physbeh.2015.08.017

Wardle, S. G., Mitchell, C. J., \& Lovibond, P. F. (2007). Flavor evaluative conditioning and contingency awareness. Learning \& Behavior, 35(4), 233-241. https://doi.org/10.3758/BF03206429

Wickham, H. (2016). ggplot2: Elegant Graphics for Data Analysis. Springer-Verlag New York. https://ggplot2.tidyverse.org

Winter, B. (2013). Linear models and linear mixed effects models in R with linguistic applications. ArXiv preprint: 1308.5499. http://arxiv.org/abs/1308.5499

Yarkoni, T. (2019). The Generalizability Crisis. PsyArXiv. https://doi.org/10.31234/osf.io/jqw35

Yeomans, M. R. (2006). Olfactory influences on appetite and satiety in humans. Physiology \& 
Behavior, 89(1), 10-14. https://doi.org/10.1016/j.physbeh.2006.04.010

Yeomans, M. R., \& Boakes, S. (2016). That smells filling: Effects of pairings of odours with sweetness and thickness on odour perception and expected satiety. Food Quality and Preference, 54, 128-136. https://doi.org/10.1016/j.foodqual.2016.07.010

Yeomans, M. R., Mobini, S., Elliman, T. D., Walker, H. C., \& Stevenson, R. J. (2006). Hedonic and sensory characteristics of odors conditioned by pairing with tastants in humans. Journal of Experimental Psychology: Animal Behavior Processes, 32(3), 215228. https://doi.org/10.1037/0097-7403.32.3.215

Yeomans, M. R., Prescott, J., \& Gould, N. J. (2009). Acquired hedonic and sensory characteristics of odours: Influence of sweet liker and propylthiouracil taster status. The Quarterly Journal of Experimental Psychology, 62(8), 1648-1664. https://doi.org/10.1080/17470210802557793

Zellner, D. A., Rozin, P., Aron, M., \& Kulish, C. (1983). Conditioned enhancement of human's liking for flavor by pairing with sweetness. Learning and Motivation, 14(3), 338-350. https://doi.org/10.1016/0023-9690(83)90021-8 